\title{
TAXA DE GERMINAÇÃO EM SEMENTES DE Plathymenia reticulata Benth. SOB CONDIÇÕES DE CASA DE VEGETAÇÃO E BOD
}

\author{
Lucimara Cruz de Souza ${ }^{1}$ \\ Adelson Lemes da Silva Júnior ${ }^{2}$ \\ Rafael Fonseca Zanotti ${ }^{3}$ \\ José Henrique Soler Guilhen ${ }^{4}$ \\ Mariana Cruz de Souza ${ }^{5}$ \\ Sustanis Horn Kunz ${ }^{6}$ \\ Fábio Demolinari de Miranda ${ }^{7}$
}

\begin{abstract}
Resumo: O objetivo desse trabalho foi avaliar a porcentagem de germinação de sementes de Plathyemenia reticulata visando a obtenção de plântulas para estudos de diversidade genética. O experimento foi conduzido em BOD (câmara de germinação) e casa de vegetação sendo instalado em fatorial simples (2Ambiente $X$ 2-Tempos), em um delineamento inteiramente casualizado composto por 180 repetições por tratamento. Contabilizou-se as sementes germinadas em 10 e 30 dias de semeadura para obtenção das porcentagens de germinação. Para verificação de diferenças entre os tratamentos, os dados foram submetidos à análise de variância (ANOVA). O experimento resultou na não interação entre os fatores avaliados e a significância entre os tempos em estudo (10 e 30 dias), tendo aos 30 dias uma porcentagem média de 43, 33\% de germinação. A ANOVA demostrou que não há diferença estatística significativa entre os ambientes, indicando que tanto as sementes em BOD como em casa de vegetação apresentaram o mesmo potencial germinativo. Mediante estes resultados observados, pode-se concluir que a avaliação da porcentagem de germinação deve ser feita aos 30 dias após a plantio das sementes e que o ambiente sendo bem controlado não influencia na porcentagem final de germinação.
\end{abstract}

Palavras-chave: Arbóreas; Propagação seminífera; Vinhático.

\footnotetext{
${ }^{1}$ Mestranda em Genética e Melhoramento/ UFES, Brasil. E-mail: lucimaracruz15@hotmail.com.

2 Mestre em Genética e Melhoramento/ UFES, Brasil. E-mail: adelsonlemes@yahoo.com.br.

${ }^{3}$ Doutor em Genética e Melhoramento/ UFES, Brasil. E-mail: faelzanotti@gmail.com.

${ }^{4}$ Mestre em Genética e Melhoramento/ UFES, Brasil. E-mail: jhguilhen@gmail.com.

5 Agronomia/UFES, Brasil. E-mail: scruz.mariana@gmail.com.

6 Prof. Doutora em Ciências Florestais/UFES, Brasil. E-mail: sustanis@gmail.com.

7 Prof. Doutor em Genética e Melhoramento/UFES, Brasil. E-mail: fademolinari@yahoo.com.br.
} 